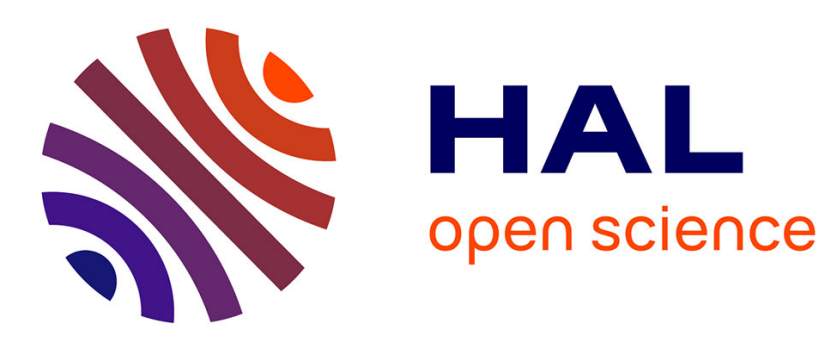

\title{
ON THE APPLICATION OF SEMI-CLASSICAL CONCEPTS TO HEAVY ION SCATTERING
}

\author{
C. Marty
}

\section{To cite this version:}

C. Marty. ON THE APPLICATION OF SEMI-CLASSICAL CONCEPTS TO HEAVY ION SCATTERING. Workshop on Semiclassical Methods in Nuclear Physics, 1984, Grenoble, France. pp.C6121-C6-122, 10.1051/jphyscol:1984614 . jpa-00224215

\section{HAL Id: jpa-00224215 https://hal.science/jpa-00224215}

Submitted on 1 Jan 1984

HAL is a multi-disciplinary open access archive for the deposit and dissemination of scientific research documents, whether they are published or not. The documents may come from teaching and research institutions in France or abroad, or from public or private research centers.
L'archive ouverte pluridisciplinaire HAL, est destinée au dépôt et à la diffusion de documents scientifiques de niveau recherche, publiés ou non, émanant des établissements d'enseignement et de recherche français ou étrangers, des laboratoires publics ou privés. 
Division de Physique Théorique , Institut de Physique Nuctéaire, B.P. 1, 91406 Orsay Cedex, Erance

Résumé - Les méthodes semi-classiques s'appliquent d'ordinaire bien aux collisions d'ions lourds. Toutefois il existe des contre-exemples. L'un est discutẽ ici.

Abstract - Semi-classical methods work quite well usually for heavy-ion collisions. However counter examples exist and one of them is discussed here.

Even at low energies, due to their large masses, collisions between heavy ions are always associated with small de Broglie wave-lengths (with respect to the geometrical characteristics of diffusing interactions). It is therefore natural to find semi-classical (s.c.) ideas largely used in that branch of physics. One is close to an "optical" situation and the words, if not quite the concepts, of diffraction, refraction, deflection functions, rainbows, glories...are currently encountered.

The s.c. methods work sometimes remarkably well. A classical example is the calculation of the pure Coulomb scattering amplitude $f_{C}(\theta)$ between point charges under an angle $\theta$. The WKB approximation associated with saddle point or stationary phase techniques give the exact result for $f_{c}$. Though surprising this can be partly understood $/ 1 /$. What follows is related to a counter example where the application of s.c. approximations yieids to a completely wrong result.

It has been recently asserted $/ 2$ / that for charged particles a forward glory is present in the elastic channel. This has to be understood in the following way. The usual optical theorem should be modified for long range interactions such as the coulomb one. For spinless particles in the incident channel a new integrated elastic cross-section $\sigma^{\prime} f^{\prime}\left(\theta_{0}\right)$ is defined as

$$
\sigma_{e l}^{\prime}\left(\theta_{0}\right)=2 \pi \int_{\theta_{0}}^{\pi}\left(d \sigma / d \Omega-d \sigma_{c} / d \Omega\right) \sin \theta \cdot d \theta
$$

where $d \sigma / d \Omega$ is the differential elastic cross-section and $d \sigma_{c} / d \Omega$ the Rutherford one. In the limit $\theta_{0} \rightarrow 0$, a "formal" calculation using the properties of Legendre polynomials yields :

$$
\sigma_{T}^{\prime}=\sigma_{e l}^{\prime}+\sigma_{R}=4 \pi \operatorname{Im} f_{N}(0) / k
$$

In (II), $\sigma_{T}^{\prime}$ is a new total cross-section, sum of the standard reaction one $\sigma_{R}$ plus the limit $\sigma_{e l}^{\prime}$ for $\theta_{0} \rightarrow 0$ of $\sigma_{e l}^{\prime}\left(\theta_{0}\right)$. $f_{N}$ is the so-called short-range amplitude and $k$ the asymptotic wave number of the colliding partners. Evaluating $f_{N}(0)$ by the stationary phase approximation it is asserted in /2/ that $\sigma \dot{t}$ oscillates when $k$ increases. These oscillations are the signature of a forward glory since they are related to properties of the deflection function.

* laboratoire Associê au C.N.R.S. 
As it has been demonstrated elsewhere /3/, equation (II) is indeed incorrect. The exact result to start with is $\left(0<\theta_{0} \leqslant \pi\right)$ :

$$
\sigma_{e l}^{\prime}\left(\theta_{0}\right)+\sigma_{R}=4 \pi\left|f_{N}(0)\right| \sin \left\{\operatorname{Arg} f_{N}(0)+2 n \log \left(\sin \theta_{0} / 2\right)\right\} / k
$$

$$
-2 \pi \int_{0}^{\theta_{0}}\left\{\left|f_{N}\right|^{2}+2 \operatorname{Re} f_{C}^{*}\left[f_{N}-f_{N}(0)\right]\right\} \sin \theta \cdot d \theta
$$

In (III) all the quantities have been defined with the exception of $n$ which is the Sommerfeld parameter $Z_{1} Z_{2} e^{2} /(\hbar v)$ between two charges $Z_{1} e, Z_{2} e$ moving with a relative velocity $v$. It has to be noted how part of the Coulomb-nuclear interference appears in the RHS of (III). Ins tead of the usual integrand $f_{C}^{*} f_{N}$ one has

$f_{C}^{*}\left[f_{N}-f_{N}(0)\right]$. The origin of this particular feature will be sketched below.

In the limit $\theta_{0} \rightarrow 0$ the integral of (III) can be shown to vanish whereas the first term of the RHS starts to oscillate more and more rapidly, being at the limit undefined but bounded. If one follows the authors of $/ 2 /$ one would, for the forward direction, average out this term. What is obtained is simply

$$
\sigma_{T}^{\prime}=0
$$

a result totally independent of the energy. One concludes that the very existence of a forward nuclear rainbow is a pure artefact.

The origin of the error in ref./2/ is not merely due to a s.c. approximation, but to the "formal" derivation of (II), rearranging terms in scalar product of Legendre expansions of $f_{C}$ and $f_{N}$. Such a method in uncontrolled since $f_{C}$ is a distribution $14 \%$. In scalar products where $f_{c}$ is involved, it has always to be multiplied by "test-functions". $f_{N}-f_{N}(0)$, which vanishes for $\theta=0$, has that property, but not $f_{N}$ in general and it is the reason of the appearence of $f_{N}-f_{N}(0)$ in (III). For a complete discussion, see $/ 3 /$.

The above remarks are rather academical since it is impossible in practice to make any measurement in the forward direction due to the enormous flux in the incident channe1. The interest of (III) is for angles $\theta_{0}$ in the region of the Coulomb nuclear interference (Fresne? zone). In this situation it is possible to give mode 1 independent upper and lower bounds to $\sigma_{R}$. This will be published elsewhere.

\section{References :}

/1/ ROWLEY N., J. Phys. A11 (1978) 1545.

/2/ HLSSEIN M.S. et a1., Phys. Lett. 114B (1982) 1.

13/ MARTY C., Zeit. Phys. A309 (1983) 261.

14/ TAYLOR J.R., Nuov. Cimento 23B (1974) 313. 